\title{
A Simple Method to Test Studios' Sound Quality
}

\author{
Lin Chen \\ Educational Science College of Chongqing Normal University \\ chenlin_800123@163.com
}

Keywords: Method; Studios' Sound Quality; Analyze; Test; Comparative Analysis

\begin{abstract}
Nowadays with the development of economy, more and more schools and establishments are building their own studios. However, due to various reasons, the sound quality of a studio may be not completely satisfactory. The professional instruments for testing the sound quality of studios are very expensive, so it is becoming increasingly important to use a simple method to test studios' sound quality. Studio is a site where light and sound is used for the creation of spatial arts. It is a regular production base for television programs, and is mainly used for recording, videotaping lectures, seminars and small-scale entertaining events. A studio's sound quality is mainly determined by reverberation time and interfering noise. In this paper, the studio of educational technology major of Chongqing Normal University will be used as an example to explain how to use simple devices to test reverberation time and interfering noise (further divided into airborne sound and knocks).[1]
\end{abstract}

\section{Test Method for Reverberation Time}

Reverberation time, a key parameter to evaluate indoor sound quality, refers to the time duration for an indoor sound from attenuating to not being heard after the sound source stops sounding.

Principle of measurement. Measure the time taken for a single-frequency sound to fall in intensity by $60 \mathrm{~dB}$. (1)

Measurement tools. A low-frequency signal generator, speakers, microphones, microphone holders, audio cables, a sound console, a computer with audio-processing software.[2]

Measurement process. (1) Use a low-frequency generator to generate a single-frequency sound signal, and have the sound spread over the entire studio through speakers driven by an amplifier.

(2) Use a professional microphone to collect single-frequency sound inside the studio, and transfer it to the audio-processing software through the sound console.

(3) Suddenly stop speakers' sounding, and record the time taken to have $60 \mathrm{~dB}$ attenuation the help of the audio-processing software.

(4) Have the low-frequency generator to generate the single-frequency signals of $125 \mathrm{~Hz}, 250 \mathrm{~Hz}$, $500 \mathrm{~Hz}, 1000 \mathrm{~Hz}, 2000 \mathrm{~Hz}$ and $4000 \mathrm{~Hz}$ respectively, and record the time taken to have $60 \mathrm{~dB}$ attenuation for each type of sound. [3]

At last, researchers got the result of the Fig. 1. 


\section{Post-analysis.}

Studio Reverberation Time (Second)

\begin{tabular}{|l|c|c|c|c|c|c|}
\hline Frequency $(\mathrm{Hz})$ & 125 & 250 & 500 & 1000 & 2000 & 4000 \\
\hline Reverberation Time & 0.30 & 0.30 & 0.30 & 0.30 & 0.30 & 0.25 \\
\hline
\end{tabular}

\section{Plot of Studio's Reverberation Time VS Frequency}

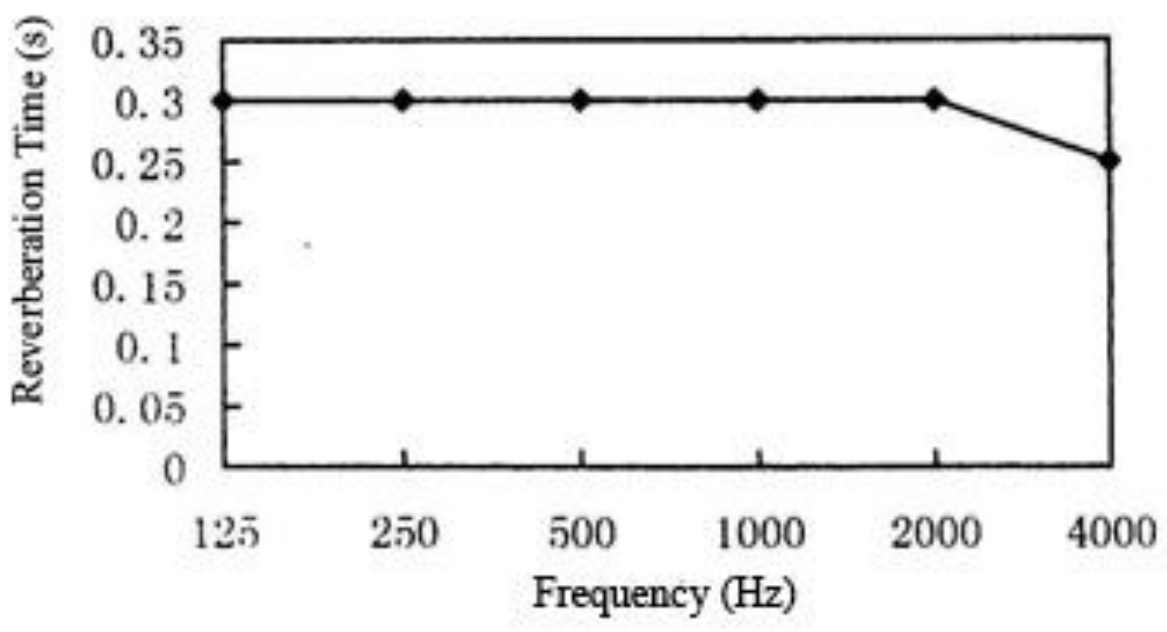

Fig. 1 Test Result

Regard to the function of a studio, the reverberation time less than $0.8 \mathrm{~s}$ is up to the standard. From the analysis, researchers can tell that the studio of the educational technology major of Chongqing Normal University is in compliance with the standard under these 6 single-frequency sounds. It is concluded that the reverberation time of this studio is in compliance with the standard. [4]

Precautions. (1) The termination of sounding from speakers cannot be done neither through switching them off nor through plugging out audio cables behind speakers. Because the switches of speakers are connected with capacitors, the sudden switch-off will cause a delay in sound transmission and sudden plugging out audio cables will cause a surge in sound volume. Both cases will impact the test results.

(2) Ensure the noise from the computer with audio-processing software is too low enough to impact the test results. If it is too loud, the computer should be moved away from the microphone far enough to avoid its impact.

\section{Test doors' ability to block airborne sound}

The noise of studio is mainly caused by poor sound insulation for doors and windows. Here researchers just explain the procedure for testing doors' sound insulation, and for windows the procedure is similar.

Principle of measurement. Use a sound level meter to measure the sound intensity outside the studio and the sound intensity inside the studio when doors are closed. Analyze the sound's attenuated value to judge whether the door is in compliance with the standard. [5]

Measurement tools. Low-frequency signal generator, speakers, sound level meter 
Measure ment process. (1). Generate a single-frequency signal outside the studio doors, and have speaks sound through an amplifier. Use the sound level meter to measure its decibel. Do the same operation inside the studio doors when they are closed, and use the sound level meter to get a decibel value. Compare these two decibel values to get the attenuated decibel value after sound transmitting through the door.

(2). Have the low-frequency generator to generate the single-frequency sound of $125 \mathrm{~Hz}, 250 \mathrm{~Hz}$, $500 \mathrm{~Hz}, 1000 \mathrm{~Hz}, 2000 \mathrm{~Hz}$ and $4000 \mathrm{~Hz}$ respectively, and compare the test results to draw a conclusion. The result is showed on table 1 .

\begin{tabular}{|c|c|c|c|c|c|c|}
\hline Frequency(Hz) & $125 \mathrm{~Hz}$ & $250 \mathrm{~Hz}$ & $500 \mathrm{~Hz}$ & $1000 \mathrm{~Hz}$ & $2000 \mathrm{~Hz}$ & $4000 \mathrm{~Hz}$ \\
\hline Sound intensity level(dB) & 60 & 65 & 70 & 75 & 80 & 85 \\
\hline Outdoor & 42 & 45 & 52 & 59 & 60 & 66 \\
\hline Indoor & 12 & & & \\
\hline
\end{tabular}

Table 1 Result of the Doors' Ability to Block Airborne Sound

We can tell from table 1 that Chongqing Normal University education technology of the door of the studio sound insulation effect within $20 \mathrm{~dB}$, but for a regular studio sound insulation effect should be above $25 \mathrm{~dB}$, so researchers think that sound insulation effect is unsatisfactory.[6]

\section{Test Doors' Ability to Block Knocks}

Principle of measurement. Use an object to evenly knock the door, and measure the sound intensity inside and outside the door respectively, and compare the test results to draw a conclusion. [7]

Measurement tools. An object which can generate even knocks (we chose the electronic back-knocking machine), sound level meter

Measure ment process. (1). Hang the electronic back-knocking machine on the door, and ensure its constant distance to the door, and then use the sound level meter to measure the sound intensity inside and outside the door.

(2). Do multiple tests to get an average value. See table 2.

\begin{tabular}{|c|c|c|c|c|c|c|}
\hline Test times & first & second & third & fourth & fifth & sixth \\
\hline Sound intensity level(dB) & 60 & 61 & 60 & 60 & 62 & 60 \\
\hline Outdoor & 43 & 43 & 41 & 44 & 44 & 40 \\
\hline Indoor & 63 &
\end{tabular}

Table 2 Result of Test Doors' Ability to Block Knocks

Analysis. Generally, the requirement for doors' sound insulation is $25 \mathrm{~dB}$ attenuation from outside to inside. After multiple tests, researchers got the average value of $18 \mathrm{~dB}$ for sound attenuation for the studio of educational technology major of Chongqing Normal University. 
Obviously it is out of standard, so researchers conclude this studio is not in compliance with the standard.[8][9]

\section{Summary}

Actually it is a large project to evaluate the designed sound quality for studios and architectural halls. The involved parameters include not only reverberation time and interfering noise, but also loudness, sound warmness, sound evenness and echo etc. This paper presents a brief introduction to a simple method to test reverberation time and interfering noise, which is just a prelude to arouse attention to the sound quality test for indoor architectural halls, such as studios. I also hope you can use the simple method introduced therein to test the sound quality of the studios at your own establishments.

(1) The time taken to have sound waves from the indoor sound source reflected back and forth in all directions and its attenuation duration is called reverberation time.

Sabine put forward the definition of reverberation time and its calculation formula as $\mathrm{T} 60=0.161 \mathrm{~V} / \mathrm{A}=0.161 \mathrm{~V} / \alpha \mathrm{S}$, where in $\mathrm{A}=$ total absorption, $\alpha=$ average absorption coefficient of room surfaces, $S=$ total surface area of the room $=$ the volume of the room.[10]

\section{References}

[1] J.Q.Wang: Sound Quality Design for Architectural Halls, published by Tianjin Science and Technology Press, 2001-07-01

[2] H.Q.Ying: Modern technology of vibration and noise, published by Aviation industry press, 2007-10

[3] W. Li, Z.Q. Hu, Q.F. Shang and Y.C. Qi: Power System Correspondence, Vol. 30 (2009) ,p.64-71

[4] K.J. Chen: Electroacoustic Technology,(1980),p.7-16

[5] Z.B. Li: Performance Equipment with Science, Vol. 9 (2005), p22-25

[6] L.Z. Su: Journal of Shangyang University, Vol. 3 (2006) No.2, p72-74

[7] L.Zhang, Y.P. Wang and J.J. Zhou: China's Medical Education Technology, Vol. 27 (2013),p42-44

[8] M.Y. Zhou: Journalist Cradle, (2006), p49-50

[9] Z.B. Wang: Scientific Information Development \& Economics, Vol. 15 (2005) No.13, p.251-252

[10] Information on http://baike.baidu.com/view/8664375.htm\#4 